Journal of Education and Vocational Research

Vol. 5, No. 4, pp. 175-185, December 2014 (ISSN 2221-2590)

\title{
Differences in Egyptian Students' Attitudes to Academic Dishonesty and Related Behaviors: The Case of Business Students
}

\author{
Dina Metwally \\ Helwan University, Egypt \\ dinametwally2001@googlemail.com
}

\begin{abstract}
Academic cheating is one type of unethical academic behaviors or academic dishonesty. The level of cheating among undergraduate students has tremendously increased. Academic cheating is crucial as it affects the credibility and predictive accuracy in university admission criteria. Despite the concern with academic dishonesty (cheating), most research has been conducted in Western context. Western research has been useful in providing in-depth understanding of causes of academic cheating however; it is uncertain whether the same research findings are applicable to Arab/Middle Eastern countries. This study focuses on academic cheating among Egyptian undergraduate students. The aim is to explore differences in students' attitudes and reported behaviors to cheating across academic years. Research findings report no significant difference among business students with regard to behaviors and attitudes to academic dishonesty. Except for few statements, students have similar responses to the used scenarios. Findings of this study have important implications to the faculty and its staff. More attention should be given to the communication of right academic behaviors to students, students' evaluation and assessment, invigilation system, punishment of wrong behaviors, and evaluation of academics.
\end{abstract}

Keywords: Academic cheating, academic years, business students

\section{Introduction}

Academic dishonesty has been an area of concern for many researchers. Researchers in the area of ethics, psychology, sociology, and higher education have been highly concerned with studying academic dishonesty (e.g. Gbadamosi, 2004; Lim \& See, 2001; Wryobeck \& Whitley, 1999). This is because it affects the credibility and predictive accuracy in university admission criteria (Gbadamosi, 2004).Further, academic institutions are primarily responsible for providing an environment that enhances students' personal developments in moral, cognitive, and physical scopes (Lim \& See, 2001).Researchers have been concerned with studying causes of academic dishonesty among undergraduate students. This is justified by the dramatic increase in the percentage of cheating students (Lim \& See, 2001; Davis et al., 1992; Sierles et al., 1980). It is argued that students cheat at different academic levels. As argued by Kleiner \& Lord (1999), students cheat because they believe that this is the only way to succeed in today's world. Researchers have introduced different explanations of cheating behaviors. One explanation is related to the influence of peer behavior. It is argued that students cheat if they see their peers do so (Gaberson, 1997; McCabe \& Trevino, 1997). Other reasons for cheating include increased pressures from schools and the need to maintain a competitive edge as some students cheat to be and/or remain distinctive (Tanner, 2004; McCabe \& Trevino, 1996). Cheating behavior is also affected by the type of the situation (Rabi et al., 2006). Also, past experience influences cheating as students who have cheated in the past will keep doing so especially if they have not been caught (Lobel, 1993).

Academic cheating is one type of unethical academic behaviors or academic dishonesty (McCabe et al., 2001). It may take place among undergraduate as well as postgraduate students. McCabe \& Trevino (1993) indicated that more than $67 \%$ of students confessed to cheating at least once. Further, Brown (2000; 1995) argued that over $80 \%$ of students admitted to committing cheating at least once. Researchers argue that younger students tend to cheat more than older students (McCabe et al., 2001; Haines et al., 1986; Anton \& Michael, 1983). However, it is unclear whether this relation is due to age or class rank. This study focuses on academic cheating among undergraduate students. The aim is to explore differences in students' attitudes to cheating across the four academic years of business schools. The study explores differences in business students' behaviors to academic cheating across the years. Factors that might cause differences in students' attitudes and behaviors to academic dishonesty are investigated and studied. The aim of the study is to provide academic institutions with methods and/or actions that can enhance the quality of education. The words academic dishonesty, academic cheating, and unethical behavior will be used interchangeably. 


\section{Literature Review}

In academic institutions, the issue of ethics is considerably important. Researchers have been highly concerned with discussing ethical and unethical actions including academic dishonesty. Academic cheating is one type of unethical academic behaviors, or academic dishonesty. Academic cheating might take place among undergraduate and postgraduate students as well as academics. However, the level of cheating among undergraduate students has tremendously increased (e.g. Young, 1998; Donahue \& Heard, 1997; McCabe \& Trevino, 1997; Diekhoff et al., 1996; Baird, 1980). Accordingly, concern with studying undergraduate students and their attitudes towards unethical behaviors has widely increased. It is argued that undergraduate students who engage in unethical behaviors will continue to do so in postgraduate study (Malouff \& Sims, 1996). Further, research has reported a positive relationship between the acknowledgement of unethical academic behavior at the undergraduate level and unethical behavior in the work place (Kalichman \& Friedman, 1992). Sierles et al. (1980) argue that cheating in college is a predictor of unethical behavior in professional life. Along with Simpson et al. (1989), Sims (1993) reports that academic dishonesty is significantly related to different forms of unethical behavior at the workplace. They argue that individuals who engage in dishonest behaviors during their undergraduate studies are more likely to engage in different forms of unethical behaviors at work. Accordingly, Understanding causes of academic cheating is important (McCabe et al., 2001).

The problem in academic cheating is that it is usually unreported by faculty staff (Rawwas \& Isakson, 2000). Academic cheating is crucial as it affects the credibility and predictive accuracy in university admission criteria (Gbadamosi, 2004). Dealing with academic cheating requires identifying the main causes of the problem. The most common reason for academic cheating, as reported in the literature, is getting a good grade (Meade, 1992; Nuss, 1984; Baird, 1980). Other reasons include a lack of study time, a heavy course workload, and a low risk of getting caught (Meade, 1992; Nuss, 1984; Baird, 1980). Rawwas \& Isakson (2000) along with Michaels \& Miethe (1989) found that cheating as an unethical behavior was inversely related with the severity of punishment. This supports Buckley et al. (2001) in their argument that unethical behavior is inhibited to the perceived probability of being caught as well as the severity of punishment of the behavior.

Research on academic cheating can be divided into two types: studies that focus on individuals' characteristics and their impact on cheating, and studies that relate academic cheating to organizational or situational factors (Gbadamosi, 2004; Rawwas \& Isakson, 2000). Gender is one of the factors that were studied in the literature to show their impact on academic cheating. Research shows different results regarding the influence of gender differences on academic cheating. Some researchers found no impact of gender differences on cheating (e.g. Sikula \& Costa, 1994; Stanga \& Turpen, 1991). Others have reported a difference between males and females with respect to academic cheating (e.g. Buckley et al., 2001; Ameen et al., 1996; Davis et al., 1992; Aiken, 1991). However, research results differ regarding which gender tends to cheat more than the other. Whilst Ameen et al. (1996) found that male students engaged more in unethical behavior than female students; Buckley et al. (2001) reported that female students had a higher probability of being engaged in unethical behavior than their male counterparts. Age is also one of the factors that were studied in the literature to show their impact on cheating. Researchers argue that younger students tend to cheat more than older students (McCabe et al., 2001; Haines et al., 1986; Anton \& Michael, 1983). However, it is unclear whether this relation is due to age or class rank.

Despite the concern with studying the impact of individual factors (e.g. age \& gender), it is argued that they are less influential than contextual factors on academic cheating (McCabe \& Trevino, 1997). Contextual factors include factors such as peer cheating behavior, peer disapproval of cheating behavior, and perceived severity of penalties for cheating. Research demonstrates that peer's behavior is a crucial factor that influences academic cheating (McCabe \& Trevino, 1997; McCabe \& Trevino, 1993; Bandura, 1986). The degree to which students perceive that their peers engage in a cheating behavior was significantly related to students' cheating behaviors (McCabe \& Trevino, 1993). McCabe \& Trevino (1993) concluded that peers' behaviors provide normative support for cheating. In such a climate, 'the non-cheater feels left at a disadvantage ` (McCabe \& Trevino, 1993, p.533). Discussion of different causes of academic cheating draws attention to the impact of organizational ethics. Specifically, it is important to explore the impact of codes of ethics and organizational climate towards ethics on academic cheating. Despite the importance of individual factors, this study focuses on the impact of institutional/organizational factors on academic cheating among undergraduate students. The impact of contextual factors (interventions) is also taken into consideration. 
Despite the concern with academic dishonesty (cheating), most research has been conducted in Western context. Although this research has been useful in providing in-depth understanding of causes of academic cheating, it is uncertain whether the same research findings are applicable to Arab/Middle Eastern countries. Differences in socio-cultural and demographic factors, as well as educational policies may cause differences. This is supported by findings of cross-cultural researches. For example, Burns et al. (1998) found that students in South Africa exhibited fewer cheating behaviors than students in America but more than the Japanese in high school education. However, Burns et al found that the cheating rates for South African in college were lower than Americans and Japanese. Nevertheless, Waugh et al (1995) examined cheating behaviors and attitudes among students from Australia, Costa Rica, United States, Austria, and former East and West Germany. Waugh et al concluded a significant difference in the perception of cheating among the six countries. Thus, conducting similar studies in Arab (Middle Eastern) countries (e.g. Egypt) is important to explore the possible impact of cultural, social, and demographic factors on students' attitudes and behaviors towards cheating. This is needed to improve the quality of educational environment within the light of country specific features.

Research Objectives: This study aims to explore differences in the attitudes and behaviors of Egyptian business students to academic cheating across academic years. Achieving the research aim requires achieving the following objectives:

- To explore differences in business students' attitudes to academic dishonesty across the years.

- To investigate differences in students' behaviors to academic dishonesty (cheating) across the years.

- To justify differences in students' attitudes and behaviors.

- To introduce possible methods of controlling academic cheating among undergraduate students in Egyptian business schools.

\section{Methodology}

Data were collected from students in the Faculty of Commerce \& Business Administration, Helwan University. Helwan University is an Egyptian public university based in Helwan. It comprises 20 faculties and 50 research centers. It is well known with Faculties of Engineering (two faculties), and Faculty of Commerce \&Business Administration. The Faculty of Commerce \& Business Administration contains unique and special departments such as foreign trade, international relations, and business information systems. Helwan University is a member of the Egyptian Supreme Council of Universities. It is a relatively new university compared to Cairo and Ain Shams Universities. It was established in 1975 by Act No. 70 of 1975. This study focused on students of the English section, as it was easier for the researcher to access them. This is because they are less in number than students of the Arabic section. Also, English section students are divided into small groups which facilitate data collection. Data collection was conducted in three stages: the pilot test, questionnaires, and interviews. These are discussed below.

Stage 1-The Pilot Test: This stage aimed to investigate issues related to students' attitudes and behaviors to cheating in different academic years. Randomly selected 40 students were interviewed by the researcher. Interviewed students were equally distributed across the four academic years. The aim of this stage was to investigate the applicability of different issues related to academic cheating (as raised in the literature) to the local context. Semi-structured interviews were used to allow students to express their views freely and provide any further comments, concerns, or suggestions. Based on the output of stage 1, questionnaires were revised to add points that were not considered as well as to ensure that the overall content of the questionnaire was suitable to the Egyptian context.

Stage 2-Questionnaires: Questionnaires were designed based on data collected from the pilot stage. Questionnaires were distributed to students at the Faculty of Commerce \& Business Administration, Helwan University. 400 students participated in the study. The response rate was $100 \%$. Students were distributed equally across the four academic years. Participants included 250 females and 150 males. The researcher was permitted to meet students in groups (according to their schedule) to give them a brief about the research, the questionnaire, the importance of their participation, and how they should fill in the questionnaire. A representative of each year administered the questionnaires to other students. Those were members of the students union (SU). They were contacted personally based on a permission taken from the Faculty Dean. Five meetings were arranged with representatives of SU including a group meeting with the four representatives and a meeting with each representative individually. During the meetings, the researcher explained the research idea and the role of each representative in the survey. The researcher was present while completing the questionnaires to answer any possible questions. Each 
session with students lasted for 40 to 60 minutes. Representatives of the SU were responsible for distribution and collection of the questionnaires which were filled in anonymously.

The questionnaire included 14 scenarios describing the behavior and attitude of Ali (a fictitious student) towards academic cheating (misconduct/dishonesty). Students were asked whether they felt Ali was right or wrong. Also, they were required to state whether they had engaged in, or would consider engaging in, Ali's behavior. To ensure that students express the true behavior, they were not given the opportunity to distinguish between "had engaged" and "would consider engaging in". A three point scale was used to express student's behavior and attitude. The three scales are: "yes", "not sure", and "no". The scenarios were adopted from Rennie \& Rudland (2003) and Lim \& See (2001). Data were analyzed using SPSS (Statistical Package for Social Scientists). Data analysis was based on using percentage frequency responses with confidence intervals. Differences between the years were analyzed using Kruskal Wallis $\mathrm{H}$ test. The Kruskal Wallis H-test is a nonparametric procedure that can be used to compare more than two populations in a completely randomized design. It is often viewed as the nonparametric equivalent of the parametric One Way Analysis of Variance (One way ANOVA), with both tests used to serve the same purpose of comparing possible differences between various groups(Green \& Salkind, 2008). Mann Whitney U test was used to compare differences between students' behaviors and attitudes across the years. The Mann-Whitney $U$ test is a non-parametric test that can be used in place of an unpaired t-test (Green \& Salkind, 2008).p Values were calculated. Differences were classed as significant where $p<0.001$. Confidence intervals were also calculated for data as significant difference was noted between the years.

Stage 3-Interviews: Justification of questionnaires' results could not be done without asking students about the scenarios mentioned in the questionnaires. Based on questionnaires' analysis, a number of points were raised. These were mainly related to justification of behaviors that differed widely across the four years of the business school. To encourage students to talk freely and openly, they were interviewed in groups. This was also done to save time. Two groups of five students each were interviewed in each year. Interviewees were randomly selected. Each interview lasted for nearly 2 hours. Interviews were useful in supporting, explaining, and justifying questionnaires' results.

\section{Results}

Students' Attitudes to Academic Dishonesty: Students were asked whether they believe Ali was wrong or not. Responses illustrate students' attitudes to academic misconduct (cheating and wrong behavior). Measuring students' attitudes to academic dishonesty was based on their responses to the scenarios in Table 1. For the majority of scenarios there was no significant difference across the years. However, five scenarios differed significantly with regard to students' attitudes to academic dishonesty across the years. Three scenarios were very highly significant whilst two scenarios were highly significant. There was a very high significant difference across the years $(p<0.001)$ in each of the following:

- Taking unauthorized materials into the exam (scenario 1 ).

- Allowing another student to copy the student's own work (scenario 8).

- Submitting an assignment that has been already submitted to another course (scenario 11).

Two scenarios were highly significant: submitting a joint work with another student as the student's own work (scenario 14, $\mathrm{p}=0.002$ ), and submitting work that has been submitted in a previous year by another student (scenario 12, $\mathrm{p}=0.007$ ). The percentage of year 1 students who felt that submitting a joint work as the student`s own work was a wrong behavior was higher than the percentage of their counterparts in other years (the percentage decreases across the years). However, the percentage of year one students who believed that submitting a piece of work (e.g. research paper, presentation) that has been submitted in a previous year by another students was a wrong behavior was lower than the percentage of other students in other academic years.

Table 1: Differences in Students' Attitudes across the Years (Students were asked whether they felt Ali was right (Yes) or wrong (No))

\begin{tabular}{rrrrrr}
\hline \multicolumn{2}{r}{ Statements } & & & & Yo \\
& & Response & Year 1 & Year 2 & Year 4 \\
\hline 1. $\quad$ Ali takes & Yes & $1(-0.6$ to 1.6$)$ & $7(-0.5$ to 1.5$)$ & $8(1.6$ to 12.4$)$ & $16(0.3$ to 11.7$)$ \\
unauthorized & No & $98(95.7$ to 100.3$)$ & $72(95.8$ to 100.2$)$ & $70(73.9$ to 90.1$)$ & $64(72.8$ to 91.2$)$ \\
material into an & Not sure & $1(-0.6$ to 1.6$)$ & $21(-0.5$ to 1.5$)$ & $22(4.4$ to 17.6$)$ & $20(4.2$ to 19.8$)$
\end{tabular}

* $\mathrm{exam}$ < 0.001 


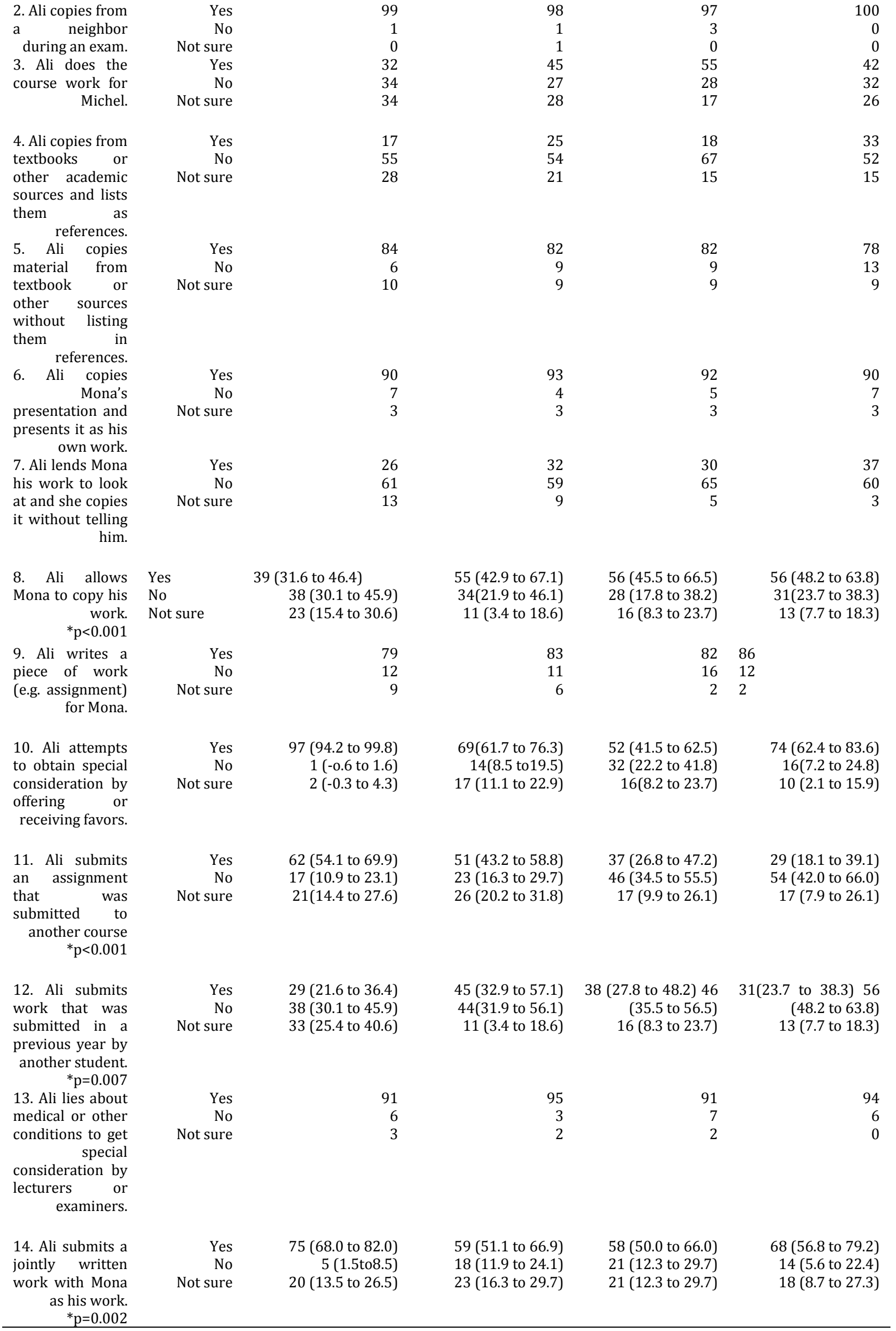


Students Reported Behaviors to Academic Dishonesty: Research findings show no significant difference for the majority of scenarios across academic years. Similar to students' responses to the scenarios in Table 1, differences in students' behaviors to academic dishonesty was found in five main scenarios. There was a very high significant difference in students' behaviors across the years $(p<0.001)$ regarding:

- Taking unauthorized materials into the exam (scenario 1).

- Submitting an assignment that has been already submitted to another course (scenario 11).

- Submitting work that was submitted in a previous year by another student (scenario 12).

- Submitting a joint work as the student's own work (scenario 14).

For scenarios1, 11, 12, the percentage of year 1 students who have engaged or would engage in any of these scenarios was less than the percentage of other students in other academic years. However, the percentage of year 1 students who have (or would) submitted a piece of work that has been submitted in a previous year by another student was higher than the percentage of other students in other academic years (scenario 14).Also, there was a high significant difference in students' behaviors across the years $(\mathrm{p}=003)$ regarding lending work to other students to copy (scenario 8$)$. The number of year 1 students who would lend their work to other students to copy was higher than their counterparts in other years. Students' reported behaviors to academic dishonesty are summarized in Table 2.

Table 2: Differences in Behaviors across the Years (students were required to state whether they had engaged in, or would consider engaging in, Ali`s behavior)

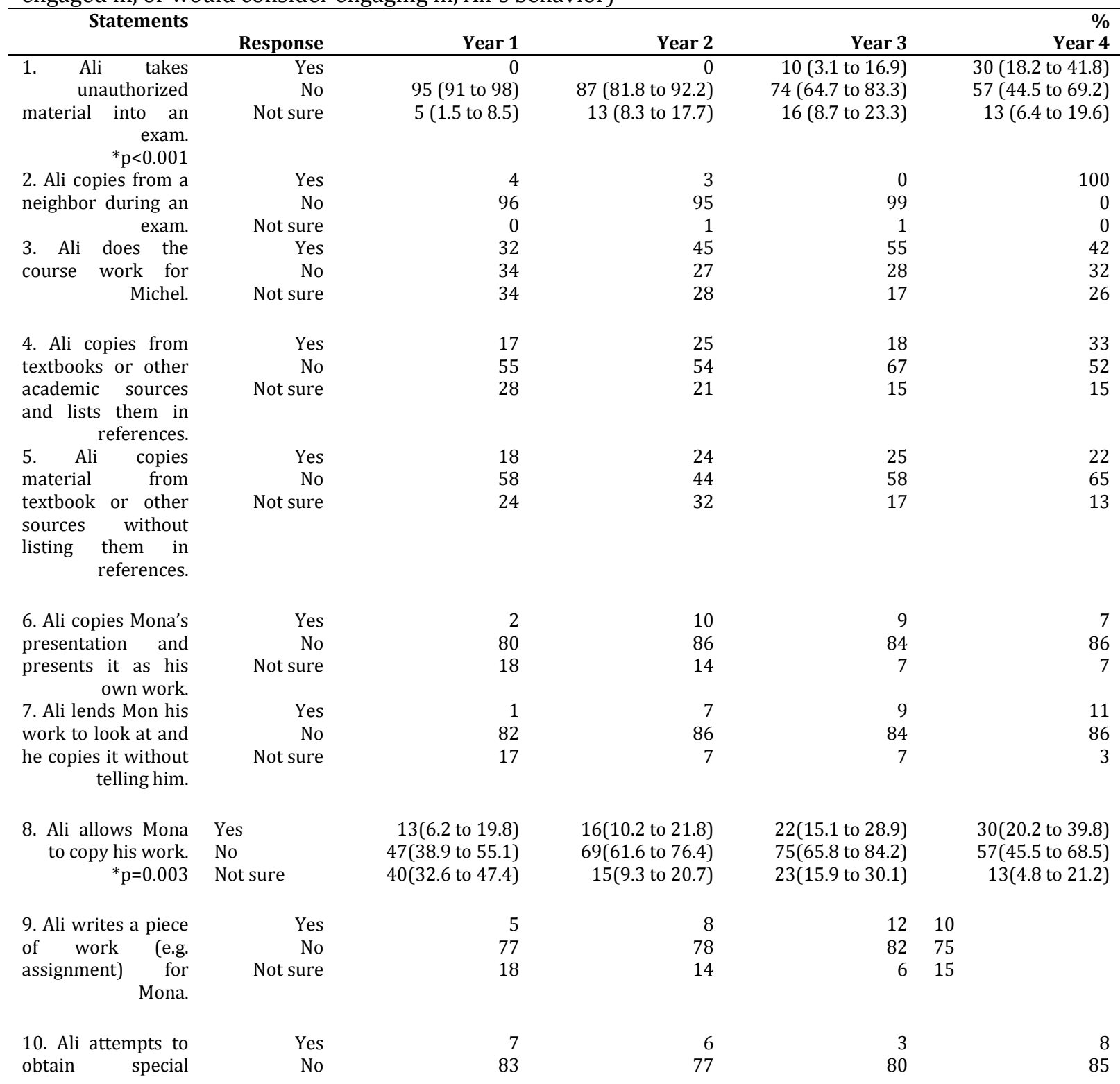




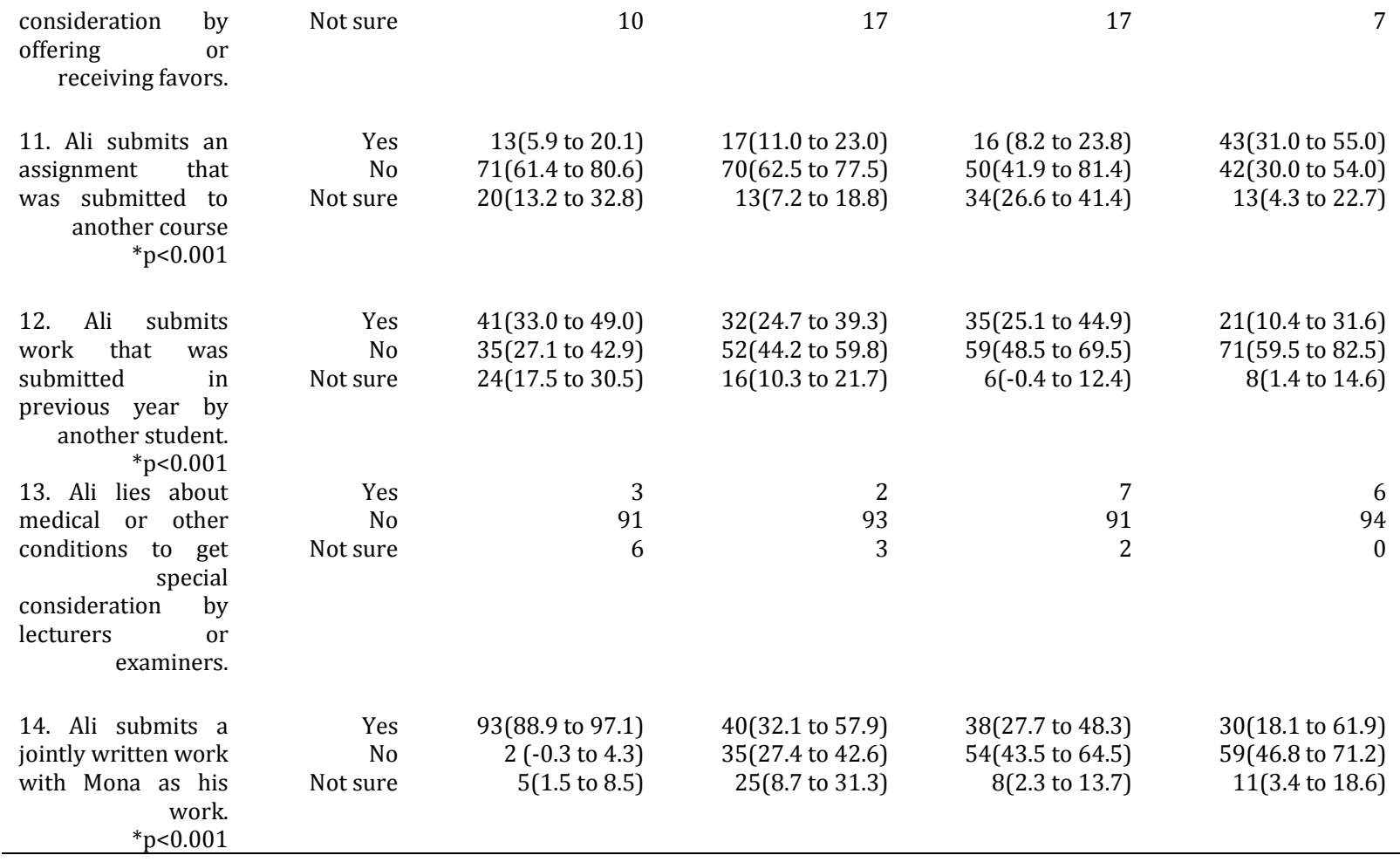

\section{Discussion}

This study aims to explore differences in behaviors and attitudes of business students across academic years. The aim is to investigate the possible impact of organizational ethics. Research findings report no significant difference among business students with regard to attitudes and behaviors to academic dishonesty. Except for few statements, students have similar responses to the used scenarios. Regarding attitudes to academic dishonesty, differences in students' responses are reported in five main scenarios. Three of these scenarios are unaccepted for first year students. However, they are accepted for other students. Specifically, first year students believe that taking unauthorized materials to the exam, submitting an assignment that was submitted in another course, and submitting another student's piece of work as the student's own work as wrong behaviors. The percentage of first year students who believe these are wrong behaviors is higher than the percentage of their counterparts in other academic years. Despite this, the percentage of first year students who agree that submitting a piece of work that has been previously submitted in previous years by another student is a wrong behavior is less than the percentage of students who believe so in other academic years. This is also true for students who agree to lend their work to another student to copy.

Despite the few differences in students' attitudes and behaviors across the years, these differences draw attention to two important points. First, the extent to which organizational ethics are clearly defined and communicated to everyone within the organization (staff and students).As explained by Aldag \& Stearns (1991), business ethics reflect a set of rules that specify the sort of behaviors that the business and its employees have to follow. In business term, ethics reflect who you are and justify your actions. It is usually assumed that what is right or wrong is the same to everyone. Thus, business ethics are applied ethics that reflect what is perceived as appropriate in the organization (Ralston et al., 1994; Velasquez, 1992). The challenge is to communicate ethics in a way that recognizes that ethics are not obvious and similar in everyone`s understanding (Gbadamosi, 2004). Thus, the way in which ethics are defined in the university is important. What is more important is the communication of ethics to university staff and students. It is argued that a more concern with the communication of university ethics results in less academic dishonesty.

Second, student's previous experience with the punishment of wrong (unethical) academic practices. One of the most common causes of academic dishonesty is the probability to be caught as well as the severity of punishment (Buckley et al., 2001). Organizations that have a harsh evaluation and assessment system can easily find out cases of academic dishonesty. Also, universities with a tough invigilation system can 
easily catch cases of cheating during an exam. A student with a negative previous experience with the punishment of academic dishonesty has lower tendency to cheat in the future. Punishment of cheating behavior is usually transmitted by the word of mouth to other students through university staff and students. This plays a significant role in controlling cheating behaviors of other students. Although questionnaires' results report differences in students' attitudes and behaviors to academic dishonesty, they are not useful in explaining and justifying these differences. Interviews are useful in introducing possible justifications for differences in students' responses to different scenarios across the years. Differences in attitudes and behaviors may be justified by one or more factors of the following:

a) Difference in Communication of Organizational Ethics across the Years: Higher integrity in year one in the areas of ethical behaviors may be justified by the faculty concern for communicating issues related to acceptable and unacceptable behaviors. It is possible to argue that the faculty gives more attention and concern to communication of ethical issues to new entrants. Faculty staff (academics and administrative) spends effort and time clarifying what is considered unethical and leads to serious problems to students. Although this is done informally inside or outside the lecture room, this is not the case with students in other years. Interviewed students report that ethical issues are rarely mentioned by university staff, except for year 1 students.

b) Influence of high school: Interviews show that scenarios that are regarded as wrong to year 1 students were regarded so in their high schools. Until they face a different experience, first year students are highly influenced by the ethical climate of their schools. Schools with high concern for ethics, positively influence students in the first year at university, and vice versa.

c) Probability to be caught and strength of punishment: Academic dishonesty is not only affected by the communication of organizational ethics, rather it is influenced by staff commitment to ensure ethical practices. Staff commitment to ethical practices reflects the faculty ethical climate. An ethical faculty climate applies rigid rules and regulations not only to students' evaluation but also to staff performance. In this ethical climate staff performance is harshly evaluated against any type of academic dishonesty. Also, faculty staff members are well trained to catch cases of wrong behaviors as well as to apply harsh punishment to these types of behaviors. Probability to be caught is one of the most important factors that influence the behavior of students in years 2,3 , and 4 . Students have a common justification for this:

"I have tried it many times and was not caught."

"If I was caught once, I would have never done it again."

Thus, the high percentage of students engaged in unethical practices (academic dishonesty) in years 2, 3, 4 is influenced by the absence of a harsh punishment system of academic dishonesty. A harsh punishment to any student's action is quickly transmitted among students. Cases of academic dishonesty that receive strong and serious punishment will stop other students from taking any action that might be strongly punished.

d) A heavy course load: The pressure of study increases in years 2, 3, and 4. The large number of subjects and exams may explain the wrong behaviors of some students in late years. While assessment and exams for year 1 students are usually based on direct questions, assessment questions in later years tend to be more analytical and creative. Also, academics try to make things easier for new entrants by relying on a specific textbook/reference. However, students in other years are required to use a wider range of textbooks and academic materials. Thus, methods of study and assessment get to be more complicated over academic years. This is considered as a critical source of pressure. To deal with the heavy study load, students in years 2, 3, 4 might have to get engaged in some behaviors that are regarded as wrong such as taking unauthorized materials to the exam, submitting another student's work as the student's own work, using academic sources without listing them in references, or submitting an assignment that was submitted to another course.

Although research findings report that year 1 students are more concerned with avoiding wrong behaviors than their counterparts in other years, there are two exceptions related to: submitting a piece of work that has been previously submitted in previous year by another student and lending work to other students to copy. The high percentage of year 1 students who believe that lending work to other students is not a wrong behavior might be justified by the new learning environment. Students in year 1 are still unfamiliar with the learning environment at the university. Thus, students feel more supported 
and secured when they work together, exchange and share knowledge. Although a supportive network environment should be created between students and academics however; the large number of students in the Faculty of Commerce \& Business Administration makes it difficult for academics to give equal time, effort, and attention to every student. Thus, year 1 students rely on their peers as a substitute to academics. Year 1 students Consider submitting a piece of work (e.g. research paper, presentation) that has been submitted in a previous year by another student as something acceptable. This reflects work complexity as well as the ignorance of this issue in the communication of ethical behavior by faculty members.

Research Limitations: Although this study explores important issues about differences in students' behaviors and attitudes to academic dishonesty, research findings should be used with caution. The study is concerned with business students (Faculty of Commerce \& Business Administration). Thus, generalizing research findings requires conducting the same study in other faculties with other educational areas (e.g. engineering, medicine, art, pharmacy). The results of this study are limited to English section students. Whether the same results apply to students of Arabic section or not is an issue that should be further investigated. Gender differences and their impact on students' attitudes and behaviors have not been explored in this study. Research shows different results regarding the influence of gender differences on academic cheating. Some researchers found no impact of gender differences on cheating (e.g. Sikula \& Costa, 1994; Stanga \& Turpen, 1991). Others have reported a difference between males and females with respect to academic cheating (e.g. Buckley et al., 2001; Ameen et al., 1996; Davis et al., 1992; Aiken, 1991). However, research results differed regarding which gender tends to cheat more than the other.

This is a cross-sectional study. Differences in students attitudes and behaviors may be related to groups studied, a reflection of the attitudes and behaviors of normal university population, or an outcomes of business school environment. Also, the time span of the business school (4 years) is not long enough to result in a real difference in behaviors and attitudes. Thus, further investigations in the Faculty of Commerce \& Business Administration are needed to decide whether the results of this study are real indications of differences in students' attitudes and behaviors across the years. Nevertheless, the learning environment is different in public and private universities. It is highly recommended to apply the same study in a private business school to identify possible similarities and differences between the education environment in private and public settings.

Research Implications: The findings of this study have important implications to the faculty and its staff. The increase in the proportion of students who engage in wrong actions in years $2,3,4$ draws attention to the following:

- Faculty concern with the communication and clarification of right and wrong behaviors to students across the years.

- Students' evaluation and assessment.

- Invigilation system.

- Penalty of wrong behaviors.

- Evaluation of academics.

The faculty has to pay more attention to the communication of ethical behavior in a university setting. Although this is done with year 1 students, it is done informally inside or outside the lecture room. Faculty management is responsible for setting a clear plan that guides the communication of organizational ethics to students across the years. Providing guidelines to new entrants regarding academic dishonesty is crucial. This should be done in the first semester and should clarify the meaning of academic dishonesty, different forms of dishonesty (e.g. in exams, assignments, presentations, quizes), and faculty policy to punish cases of academic dishonesty. This has to be done formally according to a plan set by the faculty management. Arranging a dialogue between new students and the faculty Dean is influential in this area.

Nevertheless, communication of acceptable academic behaviors has to include students of years 2, 3, 4 . Equal attention must be given to later years students. When the faculty stops talking to students about academic dishonesty, a message is conveyed to students that it is no longer an important issue. The dialogue between faculty members and students conveys a message that the faculty is highly concerned with cheating behavior and integrity. Also, an opportunity for informal discussion about academic dishonesty between students and academics should be facilitated. Meanwhile, invigilation system is 
crucial to control cheating behavior. Faculty has to train invigilators to ensure they do not give an opportunity to students to cheat and can easily catch a cheating student. A high probability to be caught reduces the proportion of students engage in academic dishonesty or a cheating behavior.

Similar to students, the faculty has to ensure academic dishonesty among academics. A harsh evaluation system must be applied by staff to find out about cases of dishonesty. The faculty must have a strong punishment policy of any case of academic dishonesty, cheating, or unethical behavior. This has to be compulsory to all staff members. Academics themselves should be periodically evaluated to ensure they apply faculty rules and regulations to avoid academic dishonesty. To ensure equity in group work assessment, attention should be paid to individual effort. One option is awarding grades to the individual effort in group work (e.g. assignment, presentation). Students might be required to write a report of their contribution/role in the group work. Peer appraisal of each others in a written report is also important. The individual report together with peer appraisal allows academics to have an overall, objective view of each student. Despite the drawbacks of this procedure (e.g. personal bias, influence of personal relationships), it is useful in reducing student's engagement in different forms of academic dishonesty (Lim \& See, 2001).

In summary, this study reports a serious problem of academic dishonesty at the university level. The problem is clearer and more serious in years $2,3,4$. These findings support other research findings (e.g. Elzubier \& Rizk, 2003; Rennie \& Rudland, 2003; Brown, 2000; Lim \& See, 2001). Academic dishonesty (cheating) is unethical and challenges students' evaluation. Cheaters get used to getting an advantage over other students. Enjoying such unfair advantage might turn to be an attitude that influences cheaters in their working life. Students, who used to cheat in different stages of their education, may rely on similar techniques to achieve their professional goals. Thus, this study contributes to understanding individuals' attitudes to cheating which can contribute to the design and implementation of organizational interventions to control unethical behaviors.

\section{References}

Aiken, L. R. (1991). Detecting, Understanding, and Controlling for Cheating on Tests. Research in Higher Education, 32, 725-736.

Aldag, R. \& Stearns, T. (1991). Management, (USA: Cengage South Western).

Ameen, E., Guffey, D. \& McMillan, J. (1996). Gender Differences in Determining the Ethical Sensitivity of Future Accounting Professionals. Journal of Business Ethics, 15, 591-597.

Anton, D. L. \& Michael, W. B. (1983). Short-term Predictive Validity of Demographic, Affective, Personal, and Cognitive Variables in Relation to 2 Criterion Measures of Cheating Behaviors. Educational and Psychological Management, 43, 467-483.

Baldwin, D. C., Daugherty, S. R. \& Rowley, B. D. (1996). Cheating in Medical School: A Survey of Second Year Students at 31 Schools. Acad Med, 71, 267-273.

Bandura, A. (1986). Social Foundations of Thought and Action, (Englewood Cliffs, NJ: Prentice Hall).

Baird, J. S. (1980). Current Trends in College Cheating. Psychology in the Schools, 17(4), 515-522.

Brown, B. S. (1995). The Academic Ethics of Graduate Students: A Survey. Journal of Education for Business, 70(3), 151-157.

Brown, B. S. (2000). The Academic Ethics of Graduate Business Students: 1993 to 1998', Journal of Applied Business Research, 16(4), 105-113.

Buckley, M. R., Beu, D. S. \& Frink, D. D. (2001). Ethical Issues in Human Resource Systems. Human Resource Management Review, 11, 11-29.

Burns, S. R., Davis, S. F. \& Hoshino, J. (1998). Academic Dishonesty: A Delineation of Cross-Cultural Patterns. College Student Journal, 32, 590-596.

Davis, S. F., Grover, C. A. \& Becker, A. H. (1992). Academic Dishonesty: Prevalence, Determinants, Techniques, and Punishment. Teaching of Psychology, 19, 16-20.

Diekhoff, G. M., Emily, E. L. \& Robert, E. C. (1996). College Cheating: Ten Years Later. Research in Higher Education, 37(4), 487-502.

Donahue, B. \& Heard, A. (1997). Cheat Feats. New York Times Magazine, 146(50789), 15.

Elzubier, M. A. \& Rizk, D. E. (2003). Exploring Perceptions and Attitudes of Senior Medical Students and Interns to Academic Integrity. Med Edu, 37, 589-596.

Gaberson, K. B. (1997). Academic Dishonesty among Nursing Students. Nurs Forum, 32, 14-20.

Gbadamosi, G. (2004). Academic Ethics: What Has Morality, Culture and Administration Got To Do with Its Measurement? Management Decision, 42(9), 1145 - 1161. 
Green, S. B. \& Salkind, N. J. (2008). Using SPSS for Window and Macintosh: Analyzing and Understanding Data', $5^{\text {th }}$ edn. ( NJ: Pearson Prentice Hall).

Haines, V. J., Diekhoff, G. M. \& LaBeff, E. E. (1986). College Cheating: Immaturity, Lack of Commitment and the Neutralizing Attitude. Research in Higher Education, 25, 342-354.

Helwan University Information Technology Center, http://itchelwan.edu.eg/, accessed on 06/05/2013.

Kalichman, M. W. \& Friedman, P. J. (1992). A Pilot Study of Biomedical Trainees' Perceptions Concerning Research Ethics. Acad Med, 67, 769-75.

Kleiner, C. \& Lord, M. (1999). The Cheating Game. US News \& World Report, 127(20), 54-66.

Lim, V. \& See, S. (2001). Attitudes Toward, and Intentions to Report, Academic Cheating among Students in Singapore. Ethics \& Behavior, 11(3), 261-274.

Lobel, T. E. (1993). Gender Differences in Adolescents' Cheating Behavior: An International Model. Person Individ Diff, 14, 275-277.

Malouff, J. M. \& Sims, R. L. (1996). Applying an Employment Motivation Model to Prevent Student Plagiarism. Journal of Education for Business, 4, 58-61.

McCabe, D. L. \& Trevino, L. K. (1993). Academic Dishonesty: Honor Codes and Other Contextual Influences. Journal of Higher Education, 64, 522-538.

McCabe, D. L. \& Trevino, L. K. (1996). What We Know about Cheating in College: Longitudinal Trends and Recent Developments. Change, 28(1), 28-33.

McCabe, D. L. \& Trevino, L.K. (1997). Individual and Contextual Influences on Academic Dishonesty: A Multicampus Investigation. Research in Higher Education, 38, 379-396.

McCabe, D., Trevino, L. \& Butterfield, K. (2001). Cheating in Academic Institutions: A Decade of Research. Ethics \& Behavior, 11(3), 219-232.

Meade, J. (1992). Cheating: Is Academic Dishonesty Par for the Course? Prism, 1(7), 30-32.

Michaels, J. W. \& Miethe, T. D. (1989). Applying Theories of Deviance to Academic Cheating. Social Science Quarterly, 70, 870-885.

National Telecom Regularly Authority, Helwan University, http://www.helwan-ntra.com/def.php?id=13, accessed on 06/05/2013.

Nuss, E. M. (1984). Academic Integrity: Comparing Faculty and Student Attitudes. Improving College and University Teaching, 32, 140-144.

Rabi, S., Patton, L. \& Fjortoft, N. (2006). Characteristics, Prevalence, Attitudes, and Perceptions of Academic Dishonesty among Pharmacy Students. American Journal of Pharmaceutical Education, 70(4), Article 73, 1-8.

Ralston, D. A., Giacalone, A. R. \& Terpstra, R. H. (1994). Ethical Perception of Organizational Politics: A Comparative Evaluation of American and Hong Kong Managers. Journal of Business Ethics, 13(12), 989-999.

Rawwas, M. Y. \& Isakson, H. S. (2000). Ethics of Tomorrow's Business Managers. Journal of Education for Business, 75, 321-330.

Rennie, S. \& Rudland, J. (2003). Differences in Medical Students' Attitudes to Academic Misconduct and Reported Behavior across the Years-A Questionnaire Study. J Med Ethics, 29, 97-102.

Sierles, F., Hendrickx, I. \& Circle, S. (1980). Cheating in Medical School. J Med Educ, 55, 124-125.

Sikula, A. \& Costa, A. (1994). Are Women More Ethical than Men? Journal of Business Ethics, 13, 859-871.

Simpson, D. E., Yindra, M. S. \& Towne, J. B. (1989). Medical Students' Perceptions of Cheating. Acad Med, 64, 221-222.

Sims, R. L. (1993). The Relationship between Academic Dishonesty and Unethical Business Practices. Journal of Education for Business, 68, 207-211.

Stanga, K. \& Turpen, R. (1991). Ethical Judgment on Selected Accounting Issues: An Empirical Study. Journal of Business Ethics, 10(10), 739-747.

Tanner, C. A. (2004). Moral Decline or Pragmatic Decision Making? Cheating and Plagiarism in Perspective. J NursEduc, 43, 291-292.

University History, Helwan University Official Page, http://www.helwan.edu.eg/arabic/?page_id=15, accessed on 06/05/2013.

Velasquez, M.G. (1992). Business Ethics: Concepts and Cases, (Englewood Cliffs, NJ: Prentice-Hall).

Waugh, R. F., Godfrey, J. R. \& Evans, E. D. (1995). Measuring Students' Perceptions about Cheating in Six Countries. Australian Journal of Psychology, 47, 73-80.

Wryobeck, J. M. \& Whitley, B. E. (1999). Measuring Students' Perceptions about Cheating in Six Countries. Australian Journal of Psychology, 47, 73-80.

Young, K. (1998). College Cheating on the Rise. Charleston Daily Mail, 3, 1A-11A. 